\title{
RESEARCH REGARDING THE PREFERENCE OF WAY OF WORKING IN COVID-19 CRISIS TIMES
}

\author{
Iudith ANCI KIS ${ }^{a^{*}}$, Alecxandrina DEACONU ${ }^{b}$, Adela JANSEN ${ }^{c}$ \\ ${ }^{a, b, c}$ Bucharest University of Economic Studies, Romania
}

\begin{abstract}
Companies and human resources professionals are putting an important amount of effort in finding the right way to organize employees and the working models during the crisis situation in order to keep employees safe and motivated and ensure the performance and continuity of their businesses. The present paper presents the results of a research in the insurance field regarding the preference of the managers for a certain type of working mode: work totally remote, totally from the office or hybrid work, based on the quality of cooperation with others and the motivation and performance of the people. The method used was a quantitative research and two focus groups performed on the managers of an insurance company, working in all departments, located in the entire country. The research shows the fact that non-sales managers appreciate more work at distance and wish to keep this facility on long run while sales managers appreciate it less and want to work as much as possible from the office. All of them consider that, generally they cooperate and communicate well within their teams but the communication and cooperation with other teams contributing to the sales process needs some upgrades. All managers and their teams feel motivated and involved and on the long run, they all believe that hybrid work will lead to insuring the motivation and performance of their teams. Nowadays, it is key to listen to the voice of people in order to boost the quality of the decision process in a certain situation.
\end{abstract}

KEYWORDS: Covid-19 crisis, work from home, hybrid work

DOI: 10.24818/IMC/2021/04.11

\section{INTRODUCTION}

Covid-19 crisis brought several changes in what concerns the way we make business, the way we manage people, the way we work, the way we perform, the way we live. What we know for now is that Covid-19 crisis have influenced worldwide the companies, countries and economies on one side, negatively because they were closed temporarily or totally but also positively because several opportunities have arisen such as digitalization fastening up, possibility to work from everywhere, new business opportunities, new ways of working and leaving, virtual mobility of human resources, virtual people processes such as recruitment, onboarding, training etc.

In this context, we consider useful to find the answer to the following questions:

a) what type of working models are being proffered by managers during Covid-19 Crisis in order to keep their teams safe, motivated and performant;

b) are the new people management practices going to stay on the long term, will managers and people keep them on the long run.

In this paper we will focus on the preference of the working models during Covid-19 crisis and we will investigate the opinions of 172 managers from an international insurance company regarding the way of working from home, office or hybrid, regarding what do they prefer for the present and

\footnotetext{
* Corresponding author. E-mail address: alina.bbelu@ gmail.com
} 
near future in order to keep their teams safe, performant, motivated and well connected to each other and others.

The result of the research and of the focus groups served as a base for the decisions taken by the Top Management and the Business Continuity Plan (BCP) management concerning the working model scenarios for 2021, under the leadership of the Human Resources (HR) team. The Human Resources Director who is part of the Top Management team is also the leader of the BCP management team.

It is well known that the insurance industry is heavily regulated, the $\mathrm{BCP}$ plans are not only necessary for internal purposes but are also requested by the regulatory authorities as part of their risk management process. Therefore, the decisions taken after such research has even more importance since it is subject to an official plan reported to the competent authorities.

It is important to realize that, the pandemic scenario was not part of the previous BCP plans due to the fact that the probability of it seemed to be zero, before Covid-19 crisis occurred therefore, this new scenario had to be developed. The existing BCP plans include scenarios for different other situations: earthquake, unavailability of employees, unavailability of offices etc.

\section{LITERATURE}

Ongoing post Covid-19 literature show compelling arguments that the large majority of employees would prefer an employer who is listening to them, who allows a flexible working model even post pandemic, accommodating different locations and schedules and different other needs.

First time mentioned by Nilles (1988), dating 1973, the "telecommuting" or "telework" (Messenger \& Gschwind, 2016), defined as the ability of employees to work from various places, from home, from "elsewhere" (Gajendran \& Harrison, (2007) are the most obvious changes determined by the pandemic period (Kramer \& Kramer, 2020).

Extensive literature has been written worldwide for different jobs, concluding that some of the existing ones could be performed from other location than the office (Dingel and Neiman, 2020), while others not, concluding that it is beneficial for both employees and employer. Deeper analysis must take into consideration personal factors, such as "individual and family factors" (Baker, Avery \& Crawford, 2007; Solıs, 2016), some factors like "self-discipline, self-motivation, ability to work independently, tenacity, self-organization, self-confidence, time management skills, computer literacy knowledge" that must be particularly looked in teleworking (Baruch, 2000).

Irawanto et al. (2021) analyzed the work from home potential predictors of job satisfaction, such as work life balance and work stress, concluding that both have an important impact, definitely being useful to be included in the HR policies. Some academics concluded that work from home "has a significant and negative effect on work-life balance (WLB), leading to a decreased job satisfaction, being close to research done before (Golden \& Eddleston, 2020), as the employees hardly managed the split between work and personal life, which may affect the creativity, innovation on a long run. Gajendran and Harrison (2007) revealed in their research that work from home determined more work and therefore more work stress, although those levels may have been reduced by family closeness (Hilbrecht et al. 2008, 2013), alienating the social isolation. According to Hilbrecht et al. (2008, 2013), work life balance is important as it has a positive influence on job satisfaction, where flexibility plays an important role.

Ongoing literature post Covid-19 show compelling arguments that the way we work, we are collaborating drastically changed and therefore further analysis should be done for suitable solutions, adapted to each particular context. Pandemic revealed, more than ever, that employees want to be heard, to openly express their opinion regarding their future working place and team collaboration, expecting to be taken into account by their respective companies (Klotz, 2021). 
In a continuous and accentuated war of talents and resources in general, also data driven analysis decision for attrition becomes important, according to Cook (2021), who based his research on 9 million employee records from global companies.

A flexible working model post pandemic, accommodating different locations and schedules and different other needs, became an important retention factor. Fowell (2021) states a recent study conducted together with Wakefield Research that almost half of employees (47\%) would likely look for a job if their employer doesn't adopt a flexible working model. The outcomes show that people are reluctant to go back to the old 9 to 5 working model, they want to be let to work at the hours they are more productive, from the place they choose at a certain moment, home or on-site when necessary for cooperation with other team mates. The highlighted benefits would be: productivity, less exposure to illness, hire talents across the globe, savings on the real estate. She also proposes to gather continuous feed-back to collect the ideas of the employees and implement them in the way of working.

In various recent studies (Elliott, 2021) we find additional inputs related to employees' perceptions about remote work during these times, regarding productivity, sense of belonging, work-life balance, anxiety, work related stress management underlying the importance of flexible working models. Again, the personal perception of on own safety and motivations are more important than ever and are non-negotiable.

A study done in several countries (United States, United Kingdom, France, Germany, Japan and Australia) that represented the base for a the 2021 Future Forum's Remote Employee Experience Index (https://futureforum.com), revealed that although people prefer a flexible and hybrid working model, where productivity (43\% higher related to location, $53 \%$ related to schedule) and sense of belongingness is higher, there is a degradation of the work-life-balance (-9.2), anxiety (-6.2) or workrelated stress management decreased especially for employees with kids. The same study revealed an interesting outcome related to productivity, where small teams' managers were less satisfied with their results $(57 \%)$ than the managers of larger teams $(67 \%)$. Also a hybrid model is preferred on a long run by younger employees and the ones with less seniority on the job, as the main driver for the remote work is the flexibility.

Another interesting recent subject exposed in the existing literature is related to the employees' adjustment factors to remote work, such as contextual and structural factors that are significant predictors, moderated by communication technology usage were companies heavily invested in pandemic and the quality of communication (Zoonen et al., 2021). So once more, paying attention to job criteria clarity, autonomy, the location change and disruption perceived are attrition factors as they facilitated the remote work adjustment, being mitigated by interpersonal relations, feeling of isolation and quality of communication process and tools. There are also several implications of the identified mentioned factors, also at theoretical level, for instance related to the theory of work adjustments and the interactional model of individual adjustment.

An interesting change in post Covid-19 literature regards the contradiction of previous studies, precisely that there is the negative relation between interpersonal trust and remote work adjustment (Zoonen et al, 2021), as this requires adaptation to new skills to face new environments. Several work profiles may significantly change due to workplace disruptions and differences in job clarity and different work independence degrees could be noticed between creative and collaborative jobs versus support functions.

We found also evidence in academic literature regarding the impact of Covid-19 on salesforce. Hartmann and Lussier (2020) for instance, analyzed the impact in sales management business-tobusiness via practitioner-oriented articles through lens of Leavitt's model of organizational change (1965), sociotechnical systems theory and four inter-related variables (social / human and structure and technical / task and technology) that may change if one is reshaped in crisis, Covid-19 or other. In addition, as in any other research on management, also related to the sales force teams, this may influence the sales workers appetite for new type of working. 
Particular to the insurance and all financial services system, the regulatory exigencies in the last years may have an impact too - subject to be studied further.

Looking to the future, researchers already foreseen the type of activities with the biggest potential for remote work, like those that include updating knowledge and interacting with computers (McKinsey, 2020), including the hybrid model for those with higher remote expectancy. This positively relates to our study's results, where support functions (non-sales) have higher appetite for remote work than sales force does.

Interesting research has been done by Russo et al. (2021) regarding supposed easy adaptable functions to work from home (work from home), like software engineers, correlating the well-being and productivity, by studying "50 psychological, social, situational, and physiological factors" finding that adaptation to lockdown through work from home was not per se a significant challenge, contrary to sales people whom are used mostly with direct people interaction according with their job specificities. Russo et al. (2021) concluded that an extensive autonomy might be positively perceived by those with high need of autonomy, and vice-versa by those who like more frameworks - which implies a personal analysis, more than just a front or support / back function.

Nevertheless, as Karesh et al. (2012) research suggested, although a lockdown is always likely to happened due to various factors (demographics, climate etc), the newly ones (viruses) make it even more predictable, so measures to be taken for further preparation and, as remote was accelerated in Covid-19 era (Meister 2020), it worth associate these with more studies related to the link between well-being and productivity, even under ongoing pandemic stress as we do now, as a stress test, knowing that being quarantined after quarantine period, add more (Brooks et al. 2020).

Yang et al. (2021) made interesting research using difference-in-difference (DiD) regarding the work from home effects isolated by other factors affecting the collaboration. Their findings were that changes attributable to work from home are for "less time on collaboration and more focus time" being dependent on previous remote work experience or not, affecting more the one with less. This makes relevant the assumption about sales personnel who applied lower remote levels than support/back function, so higher willingness to return to the offices.

The subject of productivity is worth analyzing it in order to find the right balance in Human Resources policies related to the work from home, comparing the level before and during pandemic working style.

By analyzing a sample of 10,000 skilled professionals, according to Gibbs et al. (2021), the number of working hours raised including the outside normal business hours, while the average output and productivity declined. The main factors identified were related to parents with children and women positively connected with these results, higher seniority employees scoring better. The communication costs and meeting duration increased, while uninterrupted working hours and communication with outside individuals or individual meetings with their managers, decreased. As the authors concluded, these requests a revised work from home policies, to prevent further declines or changes in the positive outcomes.

And the academic literature post Covid-19 is yet to come.

\section{METHODOLOGY}

In the present paper we study the preference of the managers from the insurance field for a certain type of working mode: work totally remote, totally from the office or hybrid. The methods used were a quantitative research based on a questionnaire and two focus groups. The questionnaire was developed through the platform called Lime Survey, a tool where a personalized survey was created. Once, the questionnaire was built up by HR and BCP team, the electronic invitation to complete the survey was sent to all managers, 172 in total, placed on Job Grades between $15-19$ according to our internal ranking based on Korn-Ferry Hay Group evaluation and methodology. This methodology uses multiple indicators to place a job on a certain level, such as accountability, 
freedom to act (competency limit), nature of impact, magnitude of impact, technical knowledge, managerial knowledge, communication and influencing skills, freedom to create strategy, multitude of challenges.

These managers are representing all departments, most of them located in Bucharest and ClujNapoca where the headquarters are but also located all over the country, in the main cities of each county, therefore we can state that they are representing the company countrywide.

The questioner had 9 questions, with two types of answering possibilities: multi choice (4 choices) and free answers. For the multi choice answers we used Likert scale with four answer options.

The 9 questions targeted the following areas:

- Communication, collaboration and joint efforts of the coordinated team;

- Communication, collaboration and joint efforts of cross departmental teams;

- Motivated and performing teams;

- Way of working: present and near future;

- Other suggestions regarding the way of working.

\subsection{Data analysis}

The response rate reached $77 \%$, therefore, 133 answers were received out of 172 . The answers to the questionnaire were collected anonymously in the Lime platform, then extracted in an excel file and processed by the HR team. The platform we used provides different types of analytics (total number of answers, split on complete and incomplete answers) but no charts. In a way, it was helpful since different types of personalized charts could be created taking into considerations what was important at the moment.

The data analyzed was structured in the following way:

$>$ Results for each question included in the survey;

$>$ Results on number of respondents;

$>$ Results on percentage of respondents;

$>$ Results of the sales division since their needs regarding the way of working differed from the other organizational structures;

$>$ Results of non-sales structures;

$>$ Charts.

Although, at the beginning the report was thought to be delivered on the total results, after seeing the clear differences in perception and proposals, the report was prepared on three axes, total, sales and non-sales.

The results were also correlated with the outcomes of the focus group meetings organized by the human resources team online, through WebEx platform, where 30 senior managers had participated from all departments, most of them participating in the quantitative survey as well. The objectives of the focus groups were to: identify the most suitable working models/scenarios and to identify the actions that help keep the people safe, motivated and performant.

The questions utilized during the focus groups were the following:

1. What are we doing well in this period when we are working massively from home and should keep doing?

2. What did your teams miss?

3. What would keep your teams motivated?

4. What would be the right working scenarios for you and your teams for the next period (1 year):

a. Mostly working from home?

b. Mostly from the office?

i. If yes, how many days

c. How do we make transversal teams work better, to communicate better no matter the workplace? $i$. Do we need to bring these teams physically together when needed or virtual collaboration is enough? 


\subsection{Results}

In order to interpret the results of the questionnaire, we analyzed quantitatively the collected data, at total and at the level of sales and non-sales respondents.

The first two questions are related to the effectiveness of the cooperation inside their teams and the cooperation with other teams. The results show that generally the cooperation is good but a quarter of the sales team managers feel that by not having the entire team at work they are less efficient and almost the same amount is unhappy with the collaboration with other teams that support them in the sales process. Not to mention that $2 \%$ of the sales managers feel that the collaboration with other teams is totally inefficient due to the fact that they are more difficult to be reached due to bad internet connection or lack of fix phone, or, in some cases due to lack of openness in cooperation with others.

Question number 1: How do you appreciate the communication, collaboration and joint efforts of your team during the Covid-19 crisis?

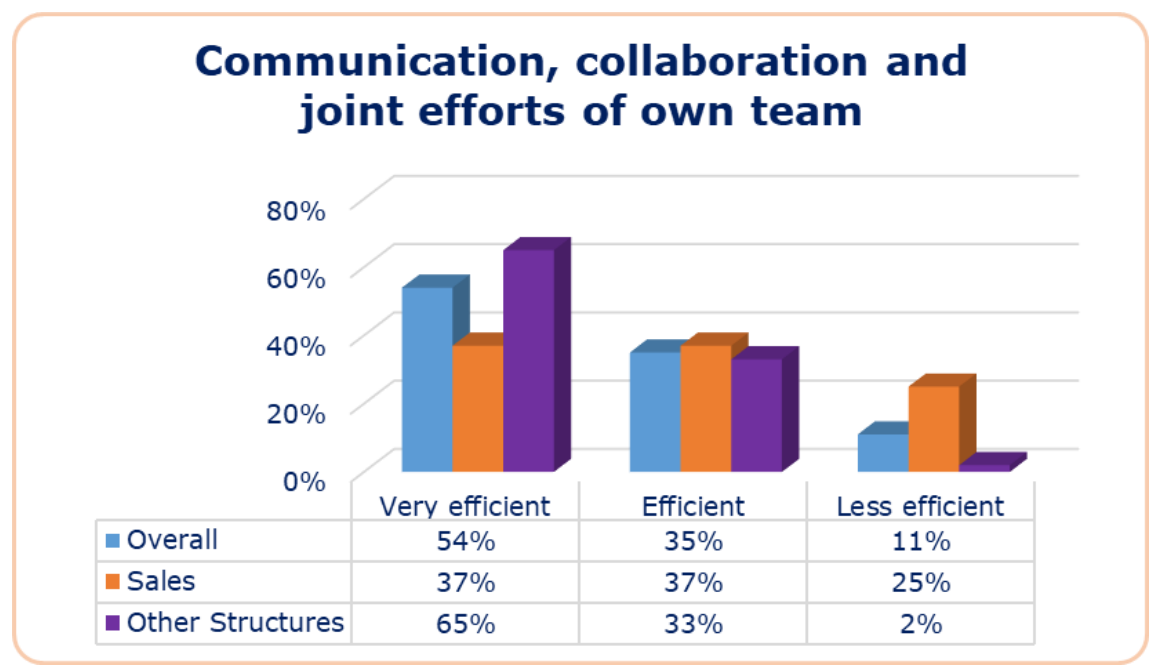

Source: Authors contribution

Question number 2: How do you appreciate the communication, collaboration and joint efforts of the team / teams you collaborate with (outside your department) during the Covid-19 crisis?

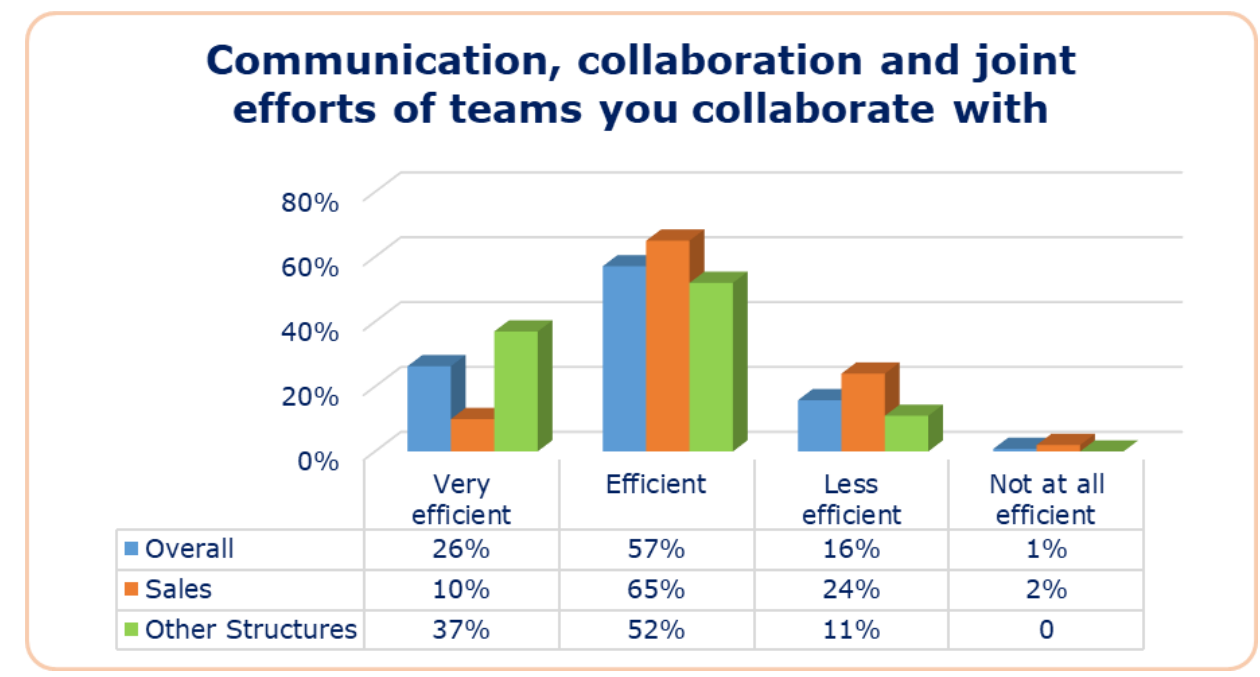

Source: Authors contribution 
The third question clarifies the appreciation regarding the mostly work from home (WFH) environment. Here we can notice that $35 \%$ of the non-sales managers, versus only $8 \%$ in sales consider that their team appreciate very much WFH while on the opposite side, $55 \%$ of the sales managers consider that their teams do not appreciate WFH, which is not the case in the non-sales teams. This lack of appreciation is coming from the fact that by not being enough in the office, they cannot control easily their teams and cannot keep contact with their clients as easy as when they were in the office.

Question number 3. Do you think your team appreciates the current way of working mainly from distance?

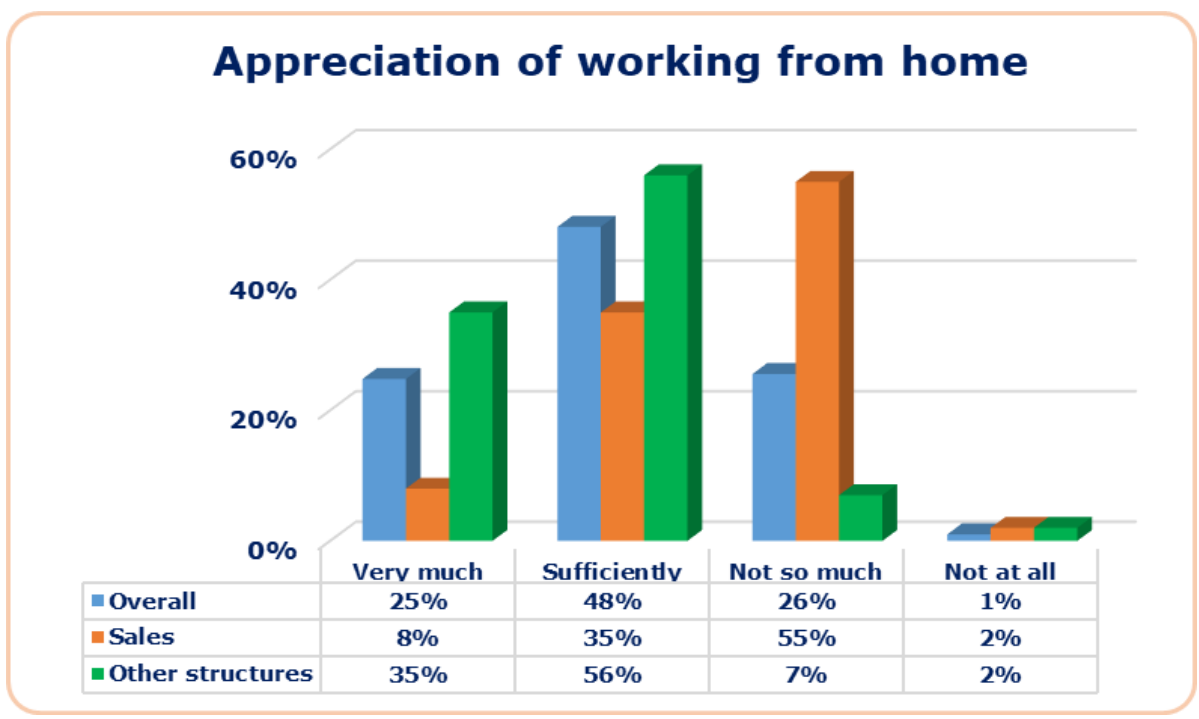

Source: Authors contribution

But even, though not all teams appreciate a higher amount of $\mathrm{WFH}$, the results of the forth question show more alignment between the 2 types of managers, most of them stating that their teams are sufficiently motivated and involved even in these circumstances. We can see that in this case motivation is not linked to the workplace but to the company, job, management and values.

Question number 4: Do you think your team is motivated and involved?

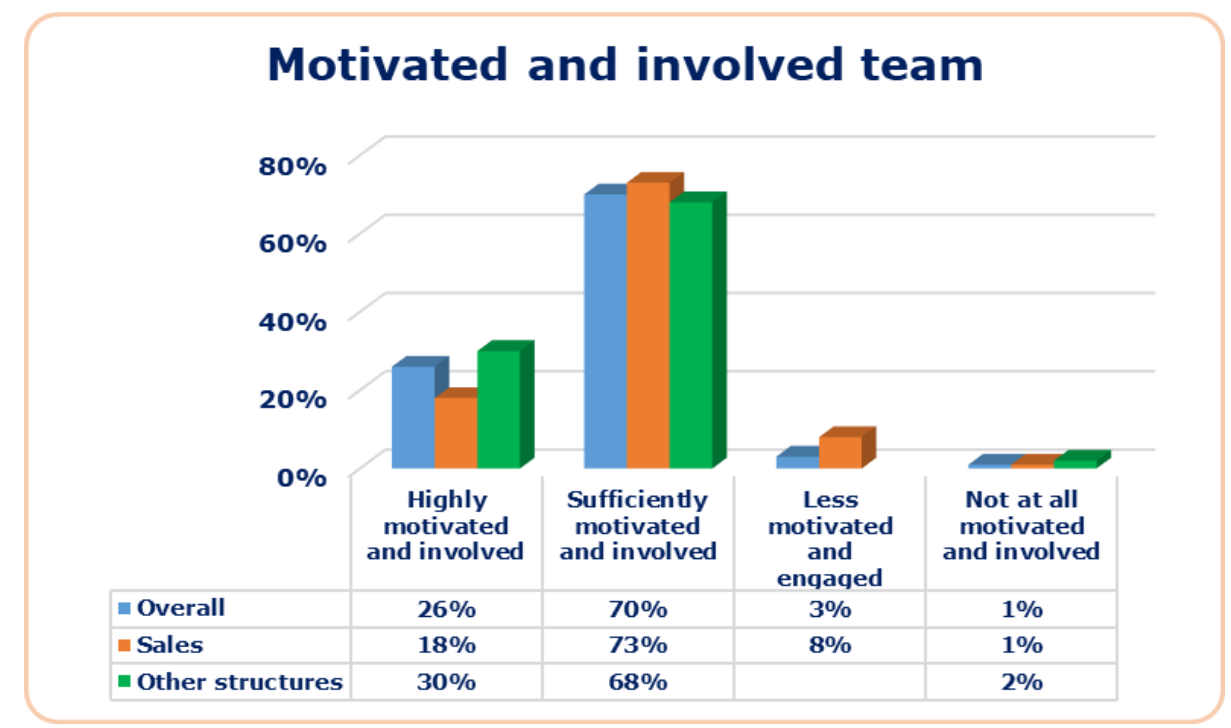

Source: Authors contribution 
The next two questions refer to results delivery in the current working model and the maintenance of the motivation and involvement in the future, as a proxy for performance. The non-sales team managers are clearly pro hybrid work and WFH while sales managers are pro work from the office and hybrid work. Only $6 \%$ of the sales managers believe in massive WFH and only $7 \%$ of the nonsales believe in going back to the office from 9:00 to 17:00, each working day which clearly raise the need to think about distinct decisions.

Question number 5: Do you think your team delivers the expected results better?

\section{Team delivers results better}

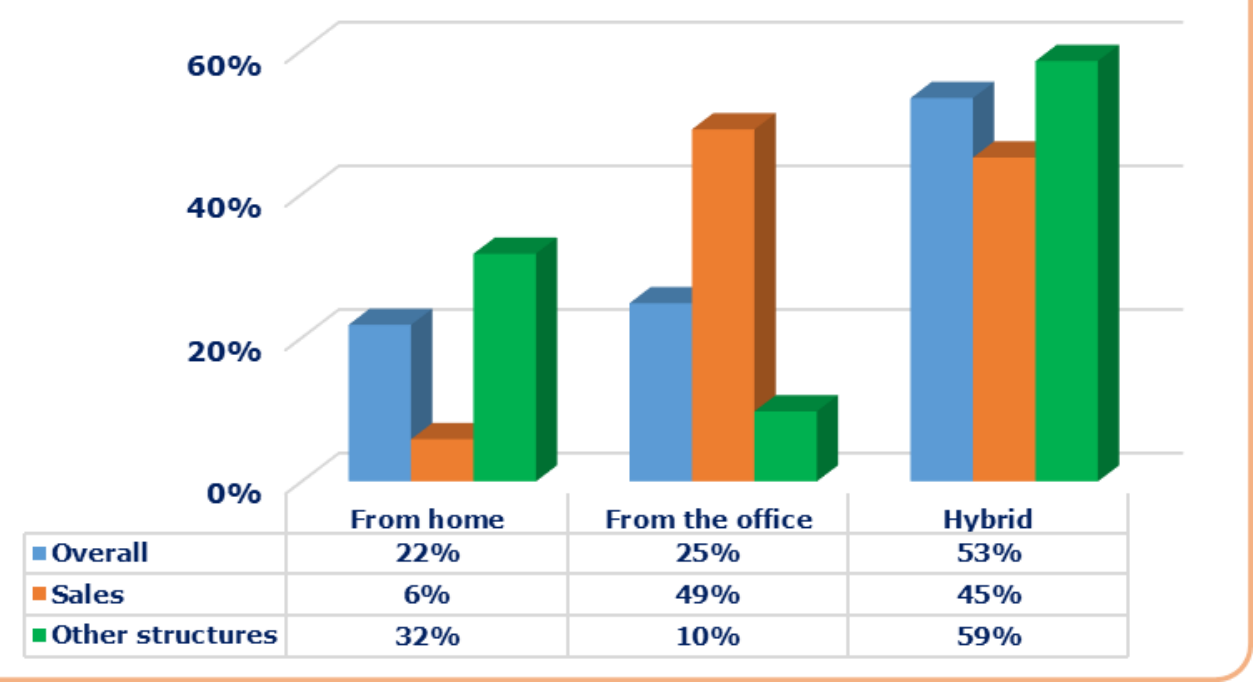

Source: Authors contribution

Question number 6: Do you think your team will remain motivated by working rather?

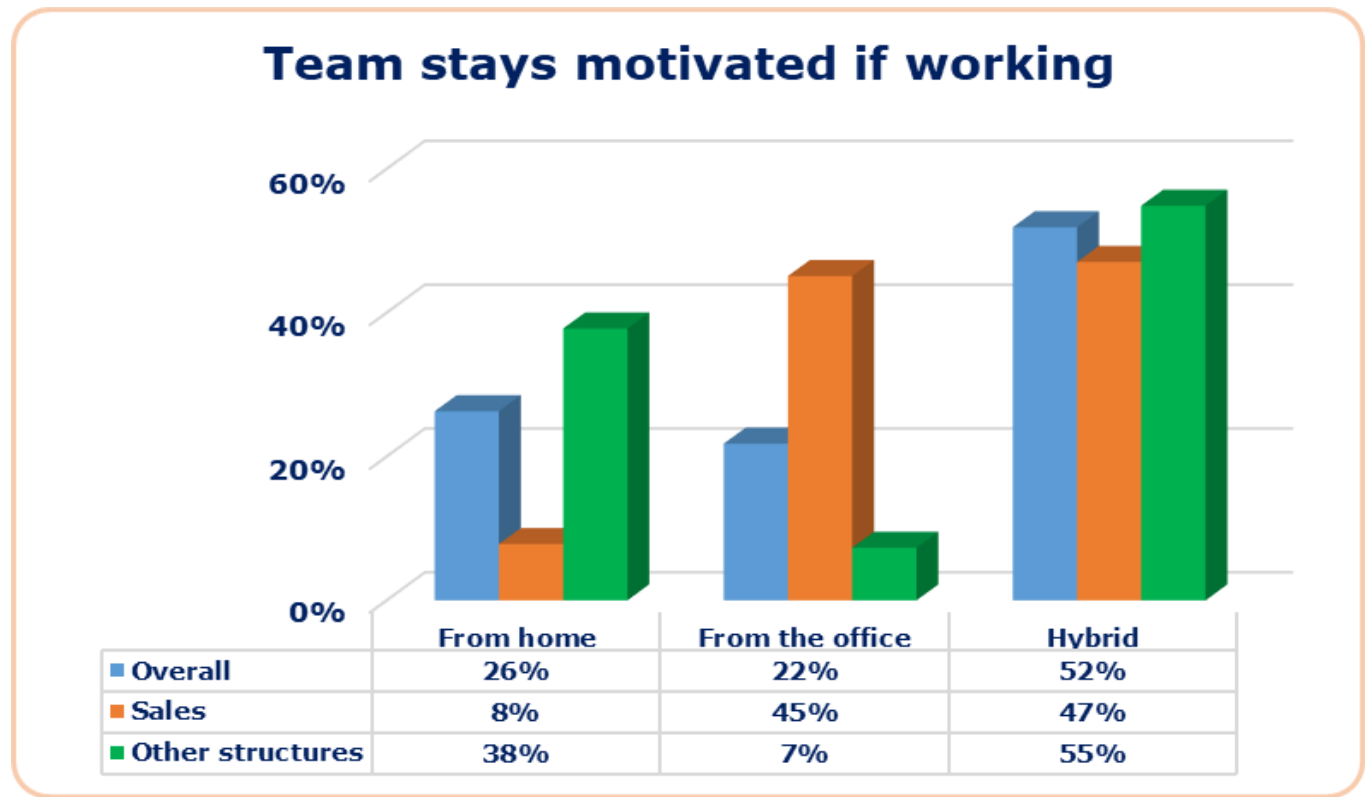

Source: Authors contribution

The next two questions are about preferences in case of high number of new Covid-19 cases per day versus low number of Covid-19 cases. Here we see that sales managers see the need to have a rule for compulsory office presence between 1-3 days even when the Covid-19 new infection rate is 
high. While, non-sales prefer to have their teams at the office on voluntary bases. Very interesting to visualize that non-sales managers link their way of working to the number of new infections because, when the infection rate is low, they are being more opened to compulsory presence.

Question number 7: What way of working do you prefer for yourself and the coordinated team in case the number of cases/ cumulative incidence remains at high level?

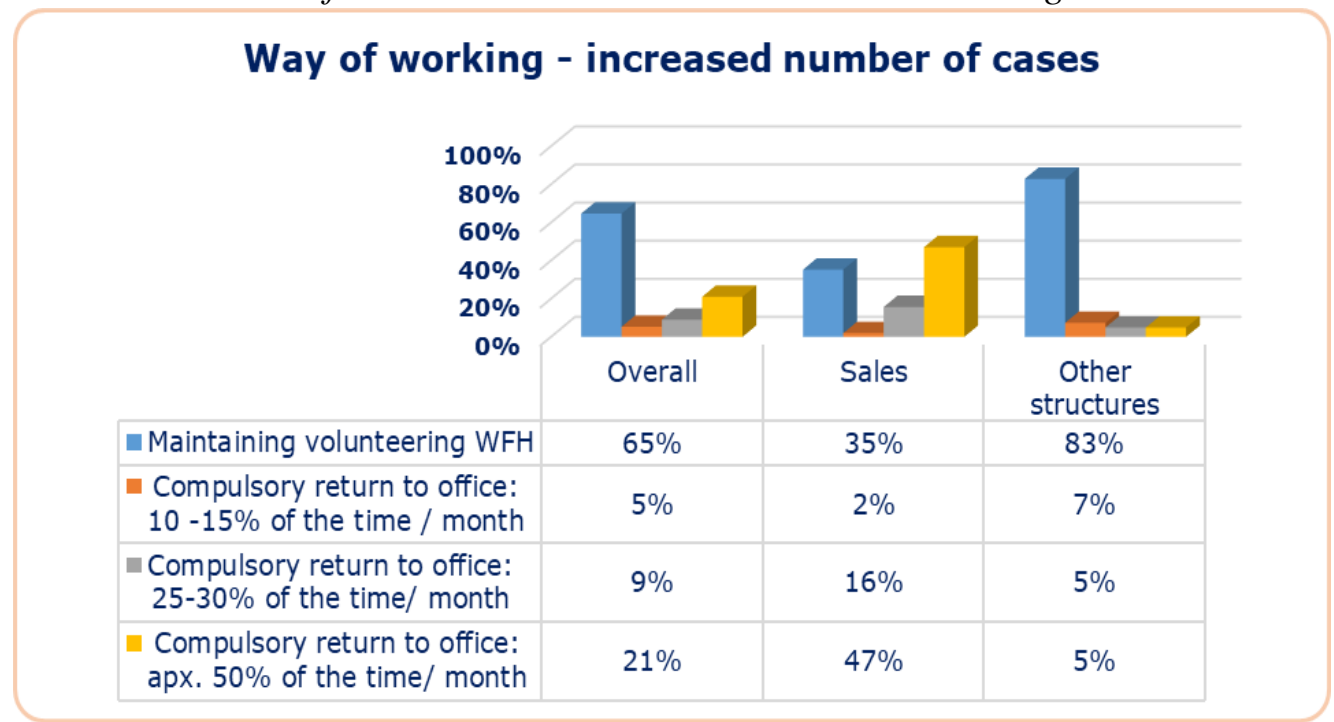

Source: Authors contribution

Question number 8: What way of work do you prefer for yourself and the coordinated team in case the number of cases will have a significant decrease?

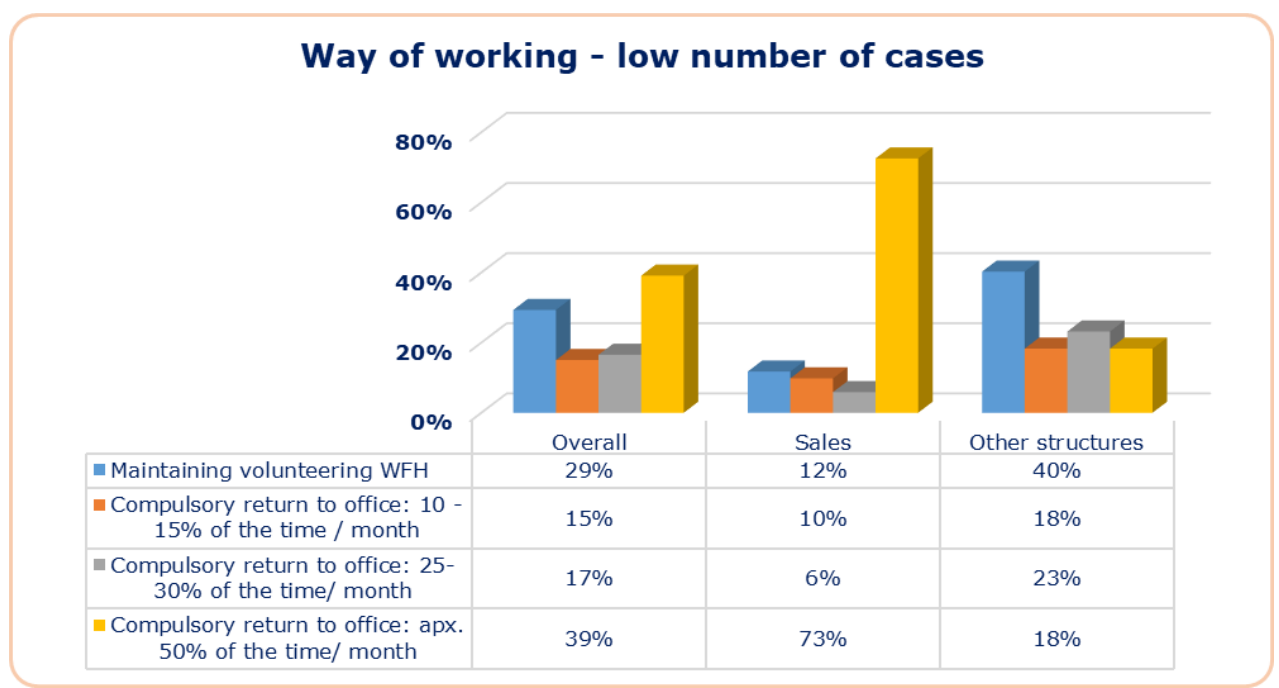

Source: Authors contribution

Question number 9: Other suggestions regarding the way of working.

The number and the quality of the answers to this question show a good level of engagement linked to the topic, and care to contribute. The suggestions given in this section are containing solutions to help employees be more efficient, communicate better, reach their results and stay safe, such as: set a standard service level agreement (SLA) between teams that are working together in the sales process in order to reach the objectives set, sales teams should be split in two and be present in the office alternatively to avoid contamination and business disruption, weekly testing of the people 
present in the office as a prevention measure, come back more days to the office after the vaccine is available, set 1-2 meetings with the CEO and other Top Management team members to communicate closer to the employees and answer to the questions that are concerning them. We also analyzed the inputs from the two focus groups and we could see again that the inputs from the non-sales managers and the sales managers were quite different, especially in what concerns the way of working. The inputs were the following:

- Non-sales managers: advocating for working massively from home, the presence in the office to be on voluntary basis (except for the positions which must perform their job at the office, such as the cleaning lady, mechanic etc.), to start coming more days only after the vaccination is implemented and progressing, to deliver training \& development programs online, to organize a monthly coffee talk with the CEO and/or a Top Management team member to communicate more directly with the people.

- Sales: advocating for massive work from the office because the client needs their physical presence, need to set up service level agreement (SLA) with other departments and divisions, need to measure collaboration Key Performance Indicators (KPIs) in order to make sure that transversal activities, processes or projects are working well and the results are being delivered, wish to see more non-sales people in the office to be easier to be reached and communicated with, implement regular Covid-19 testing for prevention reasons.

\section{CONCLUSIONS}

The conclusion of our research is that sales and non-sales managers see differently the concept of total work from home (WFH) and total work from the office but they definitely agree that hybrid work could be the common ground. Sales people feel the need to be more days at the office, while non sales employees feel less the need to be very often in the office, since they have no or less activities directly linked to the external clients.

These differences are coming from the fact that most non sales managers have been also working massively from home, not only their team members, they felt great about working from home benefitting of its advantages, such as less time spent in traffic, more time with the family etc.

On the other side, sales managers are more concerned about the sales objectives and the risk of lack of concentration if working from home. They were also willing to be present because it is important for the relationship with the client.

An outcome of the discussions from the focus groups and other data is that, beside the type of work performed by sales people which requires client related activities, there are other influencing factors that make them want to be more in the office: their average age which is over 48 years, 4 years more than the average age of the rest of the company. This could make them be more traditional in their working preferences. It is interesting that, even if sellers had been equipped 4 years before the pandemic with mobile devices to be fully digitalized, to be at a „click distance” from their clients, to be able to be modern and up to the young generation habits, they still choose to do the sales process in the office. This choice, probably has a lot to do, besides the personal preferences link to their average age and habits, with the fact that they want to make sure that they are selling and make money. The high average age of their clients are also a reason why they feel the need to be more in the office. These clients, due to their age are less digitalized and more traditional in the sales relation, willing to have direct contact with the sales counselor, ask more questions during the sales process and make sure that they „evaluate” in the direct meeting the person they offer their trust and money before signing a contract. Not to mention that, the insurance sector is highly regulated and some legal requirements make the sales process be complex and maybe, some details are difficult to be discusses or solved from the distance. 
We should be aware that not only sellers but also sales managers have some particularities. Although they are not less senior in years of experience within the company than the non-sales managers, the need to see their teams physically is not coming from lack of managerial experience but probably from the fact that their Job Grade level is on the lowest in managerial ranking, on Job Grade 15. This could be one of the reasons why their approach seems to be inclining toward direct contact, they might not trust themselves enough that they can manage their teams from distance and that they can motivate them and keep them performant if they are not psychically under their eyes, at least from time to time.

The other managers, leading non-sales teams, have a more distributed Job Grade level, between 15 and 19, good part of them being on Job Grades 17, 18 and 19 where their leadership competences are far higher, their coaching competencies are more developed, the complexity of issues they operate with every day is high as well as their decision making autonomy and limit.

The report of this survey was presented to the Top Management and the BCP management team in order to support the decision making process with relevant data and insights regarding how to organize the teams during Covid-19 times, based on type of activity and infection rate. It was a clear outcome that equal treatment through one-size-fits-all is not an option.

In the decision process, besides the data and learnings from the research, management took in consideration other elements such as: health situation, productivity and performance of the employees, seniority on the job, clarity on the role, transversal interaction, risky health problems of the employees etc.

All data and inputs, including company culture and strategy led to the following priorities and decisions:

a) Priorities: the health of the employees, the health of the company through reaching the key performance indicators, engagement, collaboration

b) Decisions for the non-sales teams: voluntary presence until the vaccine will be available but maximum presence admitted on a flor is $50 \%$ in order to keep social distancing, after the vaccine will be widely available (2nd part of the year), based on a color code approach linked to country and local infection rate, people will be present between 1-3 days per week, the presence of the entire team at the office, in the same time should be avoided for health and $\mathrm{BCP}$ reasons, unless the infection rate is close to zero.

c) For the sales team: the sales premises remain open for customers, based on a color code approach linked to country and local infection rate the sales employees will be present between half a day and 3 days per week, the presence of the entire team at the office, in the same time should be avoided for health and BCP reasons, unless the infection rate is close to zero. If infection rate is zero, or close to it, $100 \%$ of the team could be present in the office if the manager and the team agree on it, service level agreements (SLA) must be enforced or reinforced in order to foster communication and collaboration with the relevant teams in the sales process

d) General decisions, valid for all employees: employees with a risky health situation are allowed to work totally from home, managers are the ones responsible of organizing the team and activity in order to keep the team engaged and performant, project managers and project sponsors can require office presence for the project team members if it is important for the project success and team success, physical team buildings and conventions are banned until the risk of infection is low, in green color code, to remain flexible in the way of organization and decision making due to the volatility of the pandemic situation

The results of the research and the decisions taken by the Top Management and the BCP management were communicated to all employees but previously were presented to the senior middle managers in the quarterly Senior Management Meeting with the purpose of equipping well the managers with the decisions rationale and help them be able to answer to their teams if they have supplementary questions. 
In the present study, we can figure out that, for the sake of engagement, cooperation and performance, one-size-fits-all solution is not an option, that the work profile of a sales person, a front type job has different soft skills particularities than a support function, non-sales type of job, leading to an easier or more difficult adjustment to remote work in general, to a particular need of structural, relational, contextual factors or communication dynamics. This could represent an originality item of our research within the insurance industry (even if our research was limited to the managerial population of one company, but the biggest employer of the sector), highly regulated and specialized in the financial services domain. Even more, in further studies, the findings could be refined taking into account other demographic or geographic variables, evolving all employees to extract further conclusions for work satisfaction and productivity and draw action plans suitable for this sector.

\section{REFERENCES}

Baker, E., Avery, G. C., \& Crawford, J. (2007). Satisfaction and Perceived Productivity When Professionals Work from Home. Research \& Practice in Human Resource Management, 15 (1), 37-62.

Baruch, Y. (2000). Teleworking: benefits and pitfalls as perceived by professionals and managers. ew Technology, Work and Employment, 15(1), 34-49. doi:10.1111/1468-005x.00063

Brooks, S. K., Webster, R. K., Smith, L. E., Woodland, L., Wessely, S., Greenberg, N., \& Rubin, G. J. (2020). The psychological impact of quarantine and how to reduce it: rapid review of the evidence. Lancet, 395. https://doi.org/10.1016/S0140-6736(20)30460-8

Dingel, J. I., \& Neiman, B. (2020). How Many Jobs Can Be Done at Home? Journal of Public Economics, 189, 104235. doi:10.1016/j.jpubeco.2020.104235.

Fowell, T. (2021). https://envoy.com/blog/what-is-a-hybrid-work-model/

Gajendran, R. S., \& Harrison, D. A. (2007). The Good, the Bad, and the Unknown About Telecommuting: Meta-Analysis of Psychological Mediators and Individual Consequences. The Journal of Applied Psychology, 92 (6), 1524-1541. doi:10.1037/0021-9010.92.6.1524.

Gibbs, M., Mengel, F., \& Siemroth, C. (2021). Working Paper No. 2021-56. Work from Home \& Productivity: Evidence from Personnel \& Analytics Data on IT Professionals.

Golden Timothy, D., \& Eddleston, Kimberly, A. (2020). Is There a Price Telecommuters Pay? Examining the Relationship between Telecommuting and Objective Career Success. Journal of Vocational Behavior, 116, 103348.

Hartmann, Nathaniel N., \& Lussier, B. (2020). Managing the sales force through the unexpected exogenous COVID-19 crisis https://doi.org/10.1016/j.indmarman.2020.05.005

Hilbrecht, M., Shaw, Susan M., Johnson, Laura C., \& Andrey, J. (2008). 'I'm Home for the Kids': Contradictory Implications for Work-Life Balance of Teleworking Mothers. Gender Work and Organization, 15, 454-476.

Hilbrecht, M., Shaw, Susan M., Johnson, Laura C., \& Andrey, J. (2013). Remixing Work, Family and Leisure: Teleworkers'Experiences of Everyday Life. New Technology, Work and Employment, 28, 130-44.

Irawanto, Dodi Wirawan, Novianti Khusnul Rofida, \& Roz, Kenny (2021). Work from Home: Measuring Satisfaction between Work-Life Balance andWork Stress during the Covid-19 Pandemic in Indonesia. Economies 9: 96. https://doi.org/10.3390/economies9030096

Kramer, A., \& Kramer, Karen Z. (2020). The Potential Impact of the Covid-19 Pandemic on Occupational Status, Work from Home, and Occupational Mobility. Journal of Vocational Behavior, 103442.

Karesh, W. B., Dobson, A., Lloyd-Smith, J. O., Lubroth, J., Dixon, M. A., Bennett, M., Aldrich, S., Harrington, T., Formenty, P., Loh, E. H. et al. (2012). Ecology of zoonosis: natural and unnatural histories. Lancet, 380(9857), 1936-1945. https://doi.org/10.1016/S0140- 
6736(12)61678-Xhttps://slack.com/intl/en-ro/blog/transformation/emerging-hybrid-playbookflexible-work

Yang, L., Jaffe, S., Holtz, D., Suri, S., Sinha, S., Weston, J., Joyce, C., Shah, N., Sherman, K., Lee, C.J., Hecht, B., \& Teevan, J. (2020). How Work From Home Affects Collaboration: A LargeScale Study of Information Workers in a Natural Experiment During COVID-19.

McKinsey (2020). The future of work after Covid-19. https://www.mckinsey.com/featuredinsights/future-of-work/the-future-of-work-after-covid-19

Messenger, J. C., \& Gschwind., L. (2016). Three Generations of Telework: New ICTs and the (r)Evolution from Home Office to Virtual Office. New Technology, Work and Employment, 31 (3), 195-208. doi:10.1111/ntwe.12073.

Nelson, D. L. (1990). Individual Adjustment to Information-Driven Technologies: A Critical Review. MIS Q. 14, 79.

Russo, D., Hanel, Paul, H. P., Altnickel, S., \& van Berkel, N. (2021). Predictors of well-being and productivity among software professionals during the COVID-19 pandemic - a longitudinal study. Empirical Software Engineering, 26, 62. https://doi.org/10.1007/s10664-021-09945-9

Solıs, M. S. (2016). Telework: conditions that have a positive and ne gative impact on the workfamily conflict. Academia Revista Latinoamericana de Administracion, 29(4), 435-449.

van Zoonen,W., Sivunen, A., Blomqvist, K., Olsson, T., Ropponen, A., Henttonen, K., \& Vartiainen, M. (2021). Factors Influencing Adjustment to RemoteWork: Employees' Initial Responses to the COVID-19 Pandemic. Int. J. Environ. Res. Public Health, 18, 6966. https://doi.org/10.3390/ijerph 18136966 